\title{
Injection Safety Awareness and Knowledge in a Rural Population
}

\author{
Ajeet Saoji \\ Associate Professor, Department of Community Medicine \\ NKP Salve Institute of Medical Sciences and Research Center, Nagpur, India \\ Tel: 982-271-5183 E-mail: ajeet.saoji@rediffmail.com \\ Choudhury Kantibhushan \\ Post Graduate student \\ Department of Community Medicine, \\ NKP Salve Institute of Medical Sciences and Research Center, Nagpur, India \\ Deoke Aniruddha \\ Associate Professor, Department of Community Medicine \\ NKP Salve Institute of Medical Sciences and Research Center, Nagpur, India \\ Abhay Mudey \\ Department of Community Medicine Jawaharlal Nehru Medical College \\ Sawangi (M), Wardha, Maharashtra, India \\ Tel: 91-937-318-7088Ｅ-mail: abhaymudey@hotmail.com
}

Received: September 8, 2010 Accepted: September 30, 2010 doi:10.5539/gjhs.v3n1p189

\begin{abstract}
Background: About 16 billion injections are administered each year in developing and transitional countries, most of these are unnecessary and unsafe. Unsafe injection practices including the reuse of needles and syringes are a common public health problem in many countries and contribute to an estimated $40 \%$ hepatitis $\mathrm{C}$, $32 \%$ hepatitis B and 5\% human immunodeficiency virus (HIV) infections each year.

The present study was undertaken with two fold objectives to determine the average number of injections per person per year and to assess the level of knowledge and attitudes in relation to injections in a rural population of India.

Methodology: A community based cross sectional study was conducted in village located near Nagpur, India. Every alternate house was selected by systematic random sampling. Total 403 houses were served. Any member of the family above $18 \mathrm{yrs}$ of the age and who is residing in the area for more than 6 months and present at the time of visit was interviewed.

Statistical Analysis: The data was analyzed using Epi info version 3.4.1 software. Chi-square test was used as test of significance and $\mathrm{p}$ value of less than 0.05 was considered as significant

Results: A total of 403 families were interviewed. There were 1,109 person-visits to the health care providers in the last 3 months and they received 472 injections, which came out to be 0.23 injection/person/three months. In children below 5 years, $70 \%$ of injections were preventive. In $82 \%$ of injection use, disposable syringes were used. About $91 \%$ of the respondents were aware about the transmission of some diseases through unclean syringes. More than two-thirds of respondents $69 \%$ preferred oral medications to injections.

Conclusion: Interventions are needed to improve the safety of injections. These include the introduction of injection devices that prevent reuse, behavioral modification of providers, increasing awareness in the population of risks associated with injection, creating consumer avoidance of injections and demand for safety.
\end{abstract}


Keywords: Injection safety, Syringes, Rural knowledge, Injections hazards

\section{Introduction}

Injections are the most frequent medical procedure performed throughout the world. About 16 billion injections are administered each year in developing and transitional countries, most of these are unnecessary and unsafe [WHO 2002].The world health organization defines "a safe injection "as one that does not harm the recipient, does not expose the health care worker to any risk and does not result in waste that is dangerous for the community. Unsafe injection practices including the reuse of needles and syringes are a common public health problem in many countries and contribute to an estimated $40 \%$ hepatitis C, $32 \%$ hepatitis $\mathrm{B}$ and $5 \%$ human immunodeficiency virus (HIV) infections each year. A recent study indicates that each year, unsafe injections causes an estimated 1.3 million early deaths, a loss of 26 million years of life, and annual burden of US\$ 535 million in direct medical costs [WHO 2002].

Several studies have linked unsafe injection practices in Indian health setting to the transmission of blood-borne pathogens [Rajasekaran M et al 2008, Singh S et al 2000]. Recently, a large World Bank funded study, undertaken by the India CLEN Program Evaluation Network, estimated that 3-6 billion injections are provided in India each year, almost every second patient in an outpatient clinic in the country get prescription for an injection irrespective of the illness, that almost two-thirds of these injections are unsafe, and $32 \%$ have the potential to transmit blood-borne infections [Arora NK et al 2005, Hutin Y 2001]. Estimates of the average number of injections/person/year in India range from 2.4 to 5.8 [Anand K et al 2001, Hutin Y 2001 \& Kotwal A et al 2004]. In a study conducted in rural India, the authors reported high use of injections in the area. None of the Private Medical Practitioners in the village were formally trained in modern medicine [Anand $\mathrm{K}$ et al 2001].

The reason for unsafe injection is complex and includes structural, economic and socio-cultural factors. Many injections are given unnecessarily because patients overvalue them compared to oral medication [Reeler AV et al 2000]. The popularity may lie in the fact that injective medicine is quickly distributed throughout the body and have a faster effect. In turn, doctors over-prescribe injections as they believe that this satisfies patients best, even though patients are often open to alternatives. In addition, giving an injection sometimes justifies charging a higher fee for the service provided.

A number of organizations are working to the problem of unsafe injections in India like, The Indian Injection Safety Coalition, The Indian Medical Association, and an international non-governmental organization (PATH). However, most of these initiatives have focused in the more regulated formal sector and in urban areas.

The present study was, therefore, undertaken to determine the average number of injections per person per year and to assess the level of knowledge and attitudes in relation to injections in a rural population.

\section{Material and Methods}

The present community based cross sectional study was conducted in village located near Nagpur, India. This village is adapted by National Service Scheme (NSS) unit of NKP Salve Institute of Medical Sciences, and Research Centre, Nagpur. The study was undertaken from September 2009 to December 2009.The village has total 806 houses with an estimated population of 4033. Every alternate house was selected by systematic random sampling. Total 403 houses were served. Any member of the family above 18 yrs of the age and who is residing in the area for more than 6 months and present at the time of visit was interviewed assuming that an injection would be discussed in the family and respondent would know actual injection use in the family. After briefing the person about the study and its objective in the local language consent of the person was taken and the pre-tested questionnaire was administered. Due approval was obtained from institutional ethical committee.

The questions included whether any family member visited healthcare provider in last 3 months. If yes, did they receive any injection and the type of syringes used? Questions were asked to determine their knowledge regarding safety of injections and disease transmitted by unsafe injections. The data was analyzed using Epi info version 3.4.1 software. Chi-square test was used as test of significance and $p$ value of less than 0.05 was considered as significant.

\section{Results}

A total of 403 families were enrolled. $56 \%$ of the respondents were females and $64 \%$ of the respondents were in 18-30 years age group. Information was available for 2,018 family members out of which 388 were under 5 years. $32 \%$ of the respondents were illiterate. There were 1,109 person-visits to the health care providers in the last 3 months and they received 472 injections, which came out to be 0.23 injection/person/three months. If it is assumed that the incidence throughout the year was uniform, it came out to be 0.9 injection /person/year. About $10.4 \%$ of persons received at least one injection in last 3 months. 
In children below 5 years, the average was 0.42 injections/child/three months, and assuming it uniform throughout the year, it gives 168 injections /child/year. $70 \%$ injections in under 5 years population were preventive i.e., used for immunization purposes.

None of the 3 private medical practitioners practicing in the village were formally trained in modern medicine. A total of $87 \%$ injections were given at private settings. In $72 \%$ of the cases injections were given at deltoid region. Common conditions for which the prescribers used injections were fever, pain, injuries, and infections. In (82\%) of cases disposable syringes were used. About $91 \%$ of the respondents were aware about the transmission of some diseases through unclean syringes, among these $79 \%$ mentioned that HIV/AIDS, $4 \%$ abscess and $3 \%$ were aware that hepatitis can spread due to unclean syringes. About $18 \%$ also mentioned a range of other conditions like malaria, diabetes, tetanus, skin diseases and fever. $62.5 \%$ of the population was aware about the disposable syringes and were willing to buy even after knowing about the cost involved.

When association was seen between literates and illiterate in relation to awareness about disposable syringes it was considerably high in (literates $84 \%$ compared to $17 \%$ in illiterate, $\mathrm{p}<0.001$ ). Awareness of HIV/AIDS transmission through unsafe injections was high in (literates $91 \%$ compared to $32 \%$ in illiterate $p<0.001$ ). More than two-thirds of respondents $69 \%$ preferred oral medications to injections, if the cost and the efficacy was the same. Only $16 \%$ preferred an injection. The others preferred to follow doctor's orders $15 \%$. In case of efficacy being the same but cost of injection was more; even then $16 \%$ preferred injections. The reason for preferring injections was overwhelmingly because of the belief that they provide more rapid relief.

\section{Discussion}

The study revealed 0.9 injections per head per year were administered this is much lower than past Indian studies which ranges from 2.4-5.8 [Anand $\mathrm{K}$ et al 2001, Hutin Y 2001, Kotwal A et al 2004]. The studies from other countries also reported higher injections per head per year, i.e. 4.2-13.6 injections [Janjua NZ et al 2005, Talaat $\mathrm{M}$ et al 2003, Yan Y et al 2006]. This significant difference in average numbers of injections per head per year may indicate the geographical variation in injection practices; there are many socio-cultural factors that determine injection usage pattern in the community. The incidence of injection use for children below five years in present study was 1.68, while in a rural Haryana study it was 3.1 [Anand $\mathrm{K}$ et al 2001].

In this study $10.4 \%$ of population had received at least one injection in last 3 months, as compared to $17.5 \%$ in a study from rural Haryana assuming incidence as uniform throughout year [Anand $\mathrm{K}$ et al 2001] and 13\% in a study by Michelle Kermode $e t$ al, in rural north India [Michelle Kermode \& Vanlal Muani 2006]. The possible reason for this difference could be due to a different study setting.

In a village-based study in Haryana, 55\% visits to doctor resulted in injection. While In a review by Simenson et al 1999 , it was found that $33 \%$ to $50 \%$ visits to doctor resulted in injection. Our data also supported their observations as $42.5 \%$ visits resulted in use of injections. Those who were literate had significantly more awareness regarding injection use through disposable syringes (84\%) and regarding transmission of HIV/AIDS through unsafe syringes (91\%). This may be the result of various awareness campaigns of HIV/AIDS through various mass media.

It does not appear that overvaluing of injections by community members is contributing substantially to the possible overuse of injections, as only 16 per cent preferred injections, which is quite similar to 14 per cent preferring injections in the Delhi-based study [Kotwal A et al 2004] and the 18 per cent in a village-based study in Haryana. This finding challenges the often held belief of injection providers that patients prefer injections, which they sometimes use as a rationale for providing them. The most common response among persons preferring injection was they provide more rapid relief. Other responses were injection goes directly into blood, easy to give injection than oral drugs in children.

\section{Conclusion}

The issue of unsafe injection is complex; there are many factors that determine injection safety. The socio-cultural factors play an important role with safe injection practices. The study revealed 0.23 injections per head per year were administered. $45.2 \%$ visits to doctor resulted in injection. Therefore, it is important to emphasize that all illnesses do not require injections. The private sector, especially practioner is a major contributor to this injection overuse. Thus, that sector should be the key target of interventions to reduce injection frequency. Interventions that address provider's economic incentives may contribute more to reducing injection frequency. In addition interventions are needed to improve the safety of injections. These include the introduction of injection devices that prevent reuse, behavioral modification of providers, increasing awareness in the population of risks associated with injection, creating consumer avoidance of injections and demand for safety. 
The introduction of auto-disable devices may engage providers in safer injection practices. Interventions that can be easily translated and integrated into an already existing programme may be more promising in reducing injection overuse. Further research is needed to assess how many of the injections administered are unnecessary and hence could be avoided.

\section{References}

Arora NK, Bhave S, Kamath SS, and Nair MKC, Shah R. (2005). IAP workshop on safe injection practices: recommendations and IAP plan of action: Indian Pediatrics, 42: 155-61.

Anand K, Pandav CS, Kapoor SK. (2001). Injection use in a village in north India: Natl Med J India, 2001; 14: $143-4$.

Hutin Y. (2004). Injection safety in India: from assessment to policy. In Safe Injection Global Network (SIGN). Report of the Global Infection Control and Injection Safety Meeting. 20-22 October 2004, Cape Town, South Africa.

Janjua NZ, Akhtar S, Hutin YJ. (2005). Injection use in two districts of Pakistan: implications for disease prevention. Int J Qual Health Care, 17:401-8.

Kotwal A, Priya R, Thakur R, Gupta,V, Kotwal J, Seth T. (2004). Injection practices in a metropolis of north India: perceptions, determinants and issues of safety. Indian J Med Sci, 58: 334

Michelle Kermode \& Vanlal Muani. (2006). Injection practices in the formal \& informal healthcare Sectors in rural north India: Indian J Med Res, 124, November 2006, pp 513-520

Rajasekaran M, Sivagnanam G, Thirumalaikolundusubramainan P, Namasivayam K, Ravindranath C. (2003). Injection practices in southern part of India. Public Health, 117: 208-13.

Reeler AV. (2000). Anthropological perspectives on injections: a review. Bull World Health Organ, 78: 135-43.

Singh S, Dwivedi SN, Sood R, Wali JP. (2000). Hepatitis B, C and human immunodeficiency virus infections in multiply-injected kala-azar patients in Delhi: Scand J Infect Dis, 32: 3-6.

Simonsen L, Kane A, Lloyd J, Zaffran M, and Kane M. (1999). Unsafe injections in the developing world and transmission of blood borne pathogens: A review. Bulletin of the World Health Organization, 77(10): 789-800.

Talaat M, el-Oun S, Kandeel A. (2003). Overview of injection practices in two governorates in Egypt. Trop Med Int Health, 8:234-41.

WHO. (2002). Fact Sheet No. 231: Safety of injections.

Yan Y, Zhang G, Chen Y, et al. (2006). Study on the injection practices of health facilities in Jingzhou, district Hubei, China. Indian J Med Sci, 60:407-16.

Table 1. Association between literates and illiterate in relation to awareness about Disposable syringes

\begin{tabular}{|l|c|c|c|}
\hline Educational Status & Aware (\%) & Not aware (\%) & Total \\
\hline Literate & $230(84)$ & $44(16)$ & 274 \\
\hline Illiterate & $22(17)$ & $107(83)$ & 129 \\
\hline Total & 252 & 151 & 403 \\
\hline
\end{tabular}

$\mathrm{Chi}^{2}=167.48 \mathrm{df}=2 \mathrm{p}<0.00001$ (Highly significant)

Table 2. Association between literates and illiterate in relation to awareness about HIV/AIDS through unsafe injections

\begin{tabular}{|l|c|c|c|}
\hline Educational Status & Aware (\%) & Not aware (\%) & Total \\
\hline Literate & $249(91)$ & $25(09)$ & 274 \\
\hline Illiterate & $41(32)$ & $88(68)$ & 129 \\
\hline Total & 290 & 113 & 403 \\
\hline
\end{tabular}

$\mathrm{Chi}^{2}=151.79 \mathrm{df}=2 \mathrm{p}<0.00001$ (Highly significant) 